\title{
Do Squirrels in Human Disturbed Areas become Habituated to Humans? A Measure of Flight Initiation Distance across Disturbance Gradients
}

\author{
Megan D. Bjordal*
}

\begin{abstract}
Human population growth results in destruction of natural habitats, although some animals are adapting to living in areas with human disturbance. North American red squirrels (Tamiasciurus hudsonicus) may be one such species that is successfully adapting to living alongside humans. Flight initiation distance, the distance at which an animal flees from an approaching predator, may act as an indicator of habituation to humans. I predicted that if North American red squirrels were habituating to humans, their flight initiation distance would decrease along a gradient of increasing human disturbance. To examine this, I measured flight initiation distances of 39 North American red squirrels across eight sites, classified as low, medium or high human disturbance areas. No significant difference was found in mean flight initiation distances between disturbance levels, indicating that squirrel flight initiation distance may not be sensitive to small scales of human disturbance gradients.
\end{abstract}

Keywords: flight initiation distance, habituation, human disturbance, squirrel, Tamiasciurus hudsonicus

\section{Introduction}

As the human population expands, so does our impact on nature (Bayne and Hobson 1998). Highly-mobile species that are generalists in both food and habitat preference seem to have the best chances of survival in human disturbed areas; they may even benefit from the artificial food sources that human-populated areas can provide (Bayne and Hobson 2000; Engelhardt and Weladji 2011). Living in areas populated by humans may lead to habituation, whereby the animal becomes desensitized to human presence by repeated exposure (Cooper et al. 2008; Engelhardt and Weladji 2011; McCleery 2009). Flight initiation distance, the distance at which a potential predator can approach an animal before it flees, can be used as a measure of habituation (Engelhardt and Weladji 2011; McCleery 2009). Flight initiation distance is determined by balancing the costs and benefits the animal faces for remaining still or fleeing (Cooper and Frederick 2007; Dill and Houtman 1989; Engelhardt and Weladji 2011). Optimal escape theory suggests that an animal's

\footnotetext{
*Department of Biology, College of Arts and Science, University of Saskatchewan, Saskatoon, SK, Canada Correspondence: meg.bjordal@usask.ca 
decision to flee is flexible, based on maximum fitness possible from remaining stationary versus fleeing (Cooper and Frederick 2007; Engelhardt and Weladji 2011).

Squirrels are one of the many wildlife species that has had to adapt to living in human impacted areas (Bayne and Hobson 1998; Bayne and Hobson 2000; Cooper et al. 2008; Engelhardt and Weladji 2011; McCleery 2009). In central Saskatchewan, there are two species of squirrels: northern flying squirrels (Glaucomys sabrinus) and the North American red squirrel (Tamiasciurus hudsonicus) (Bayne and Hobson 1998). The North American red squirrel is diurnal, easily identifiable and relatively abundant, making them a good model species for human habitation studies. They are a forest generalist (Bayne and Hobson 2000) and known to feed largely on conifer cones (Brigham and Geiser 2012), wild mushrooms and hazelnuts in this region (personal communication with local residents). Red squirrels are territorial and may defend large areas containing multiple middens, where they store cones underground for food during the winter (Brigham and Geiser 2012; Larsen and Boutin 1994; Larsen and Boutin 1995). Identification and understanding of wildlife species adapted to living in areas impacted by humans is valuable to conservation management (McCleery 2009).

If squirrels regard humans as predators, this will affect their flight initiation distance when approached by a person (Cooper et al. 2008; Engelhardt and Weladji 2011). My hypothesis was that if squirrels can become habituated to humans, then squirrels in densely human-populated areas will have a shorter flight initiation distance when approached by a human than squirrels in less populated areas.

\section{Methods}

\section{Study area}

I observed North American red squirrels in the southern boreal mixed-wood forest near Christopher Lake and Emma Lake in north-central Saskatchewan. To find the squirrels, I randomly surveyed the sampling areas. I sampled a variety of locations to achieve a gradient of human-populated sample areas and prevent repetitive sampling. Low human disturbance areas were characterized as having mostly natural ground cover, no public roads, and low human land use. Squirrels in low disturbance areas were sampled at Kenderdine Campus and in forest trails near Kenderdine Campus and Kinasao Camp $(n=14)$. Medium human disturbance areas were characterized as areas that may have had some small clearings and quiet roads, but with natural ground cover around and between the cleared areas, with seasonal or infrequent human use. Medium disturbance areas were sampled at Murray Point Overflow campground and trails near Okema Camp $(n=10)$. High human disturbance areas were characterized as areas having little natural ground cover around clearings, well used roads, and year-round human habitation and use. Squirrels in high disturbance areas were sampled at Kinasao Camp and residential neighbourhoods around Kenderdine Campus and Kinasao Camp $(n=15)$.

\section{Sampling}

I sampled between 9:00h and 20:00h, with the majority of sampling taking place between 9:30h and 15:0oh. Once I spotted a sitting squirrel, I slowly approached it until it took flight. I used a measuring tape to measure the distance between myself and the location the squirrel fled from. To ensure the squirrel was reacting to me and not other stimuli, I tried to make sure the squirrel was still and did not appear distracted before I approached it. I also noted the squirrels' position before flight: tree, just off ground (less than two metres off the ground and not in a tree, usually on a fallen log or stump) or on the ground. Of the 39 squirrels sampled, I recorded three squirrels sitting greater than five metres above the ground in trees, but their flight initiation distances were not included in statistical analyses as the safety of the tree may present an atypical flight distance. The other variables recorded included the time of day, if the squirrel was in the open or under brush, vocalizations, and any other notable behaviour.

\section{Statistical analyses}

I used a one-way ANOVA to test for a significant difference in the mean flight initiation distances between disturbance types. To test for significant differences between squirrel position, ground or off-ground, and ground cover, open or bush, I used an independent, two samples t-test. All statistical tests were conducted using Minitab.

\section{Results}

No significant differences between disturbance types, ground cover or position were observed in regards to flight initiation distances (all $P>0.05$ ).

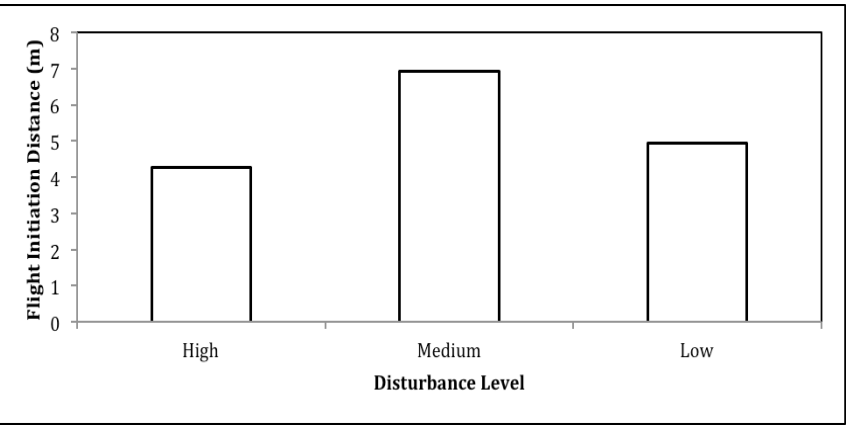

University of Saskatchewan Undergraduate Research Journal 
Figure 1: Mean flight initiation distance of red squirrels (Tamiasciurus hudsonicus) at three levels of human disturbance, high $(n=13)$, medium $(n=10)$ and low $(n=13)$ in central Saskatchewan, measured August 2014.

There was no significant difference between mean flight initiation distances across the three disturbance levels (ANOVA; $F=1.60, P=0.218$ ). Across all disturbance levels, the means were within three metres of each other; the medium disturbance level showed the highest mean flight initiation distance, and in the high and low disturbance areas the mean flight initiation distances were within a meter of each other (mean \pm SE: high $=4.27 \pm 0.975 \mathrm{~m}, n=13$, medium $=6.91 \pm 1.51 \mathrm{~m}, n=10$, low $=4.94 \pm 0.697 \mathrm{~m}, n=13$; Fig. 1). The medium disturbance level had the largest individual flight initiation distance $(16.72 \mathrm{~m})$, and the high disturbance level had the lowest $(0.59 \mathrm{~m})$. Both of these may be outliers, particularly the largest flight initiation distance as it was over twice the distance of the mean. When this large flight initiation distance was excluded in the calculation for the medium disturbance level, the mean dropped to $5.82 \pm 1.16$ metres, bringing it within two metres of the means of the high and low disturbance areas.

Out of the 39 squirrels sampled, 15 vocalized, but all vocalizations occurred when the squirrel was safely covered under brush or up a tree. Additionally, it was noted that when I was within approximately two metres of the squirrel it did not vocalize, but when further away it did. Once in a tree, some squirrels appeared to freeze and remain still for as long as I remained nearby (about five to fifteen minutes), while others continued normal behaviours and some curious individuals even approached me, lowering down the tree towards me, but always remaining positioned above me.

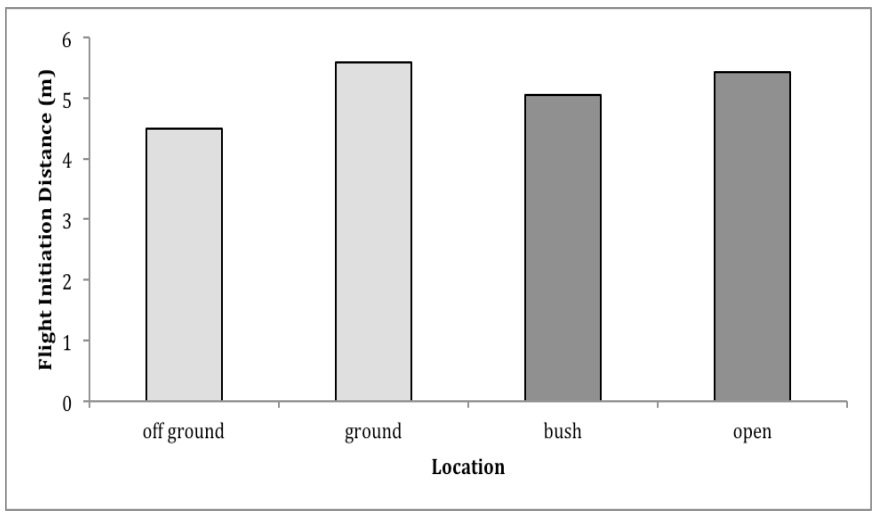

Figure 2: Mean flight initiation distance for red squirrels (Tamiasciurus hudsonicus; $n=36$ ) according to position or ground cover type, measured in central Saskatchewan, August 2014.
There was no significant difference between ground and off-ground locations (t-test; $T(8)=0.51, P=0.626$ ), nor bush and open locations (t-test; $T(33)=-0.30, P=0.764$ ). The mean flight initiation distances of squirrels directly on the ground versus just off the ground were within one meter of each other (mean $\pm \mathrm{SE}$ : ground $=5.46 \pm 0.609 \mathrm{~m}, n=$ 28 , off-ground $=4.49 \pm 1.81 \mathrm{~m}, n=8 ;$ Fig.2). The mean flight initiation distances of squirrels in open areas versus bush cover were within half a meter of each other (mean \pm SD: open $=5.43 \pm 0.819 \mathrm{~m}, n=18$, bush $=5.06 \pm 0.927 \mathrm{~m}, n=18$; Fig. 2). Between both these variables, ground cover and location to ground, the mean flight initiation distances were all within a meter of each other (Fig. 2).

\section{Discussion}

I found no evidence to support my hypothesis that red squirrel habituation to humans influences flight initiation distance. No significant differences were found in mean flight initiation distances across disturbance gradients (low, medium, high), initial position (ground, off-ground) or ground cover type (open, bush). In similar studies on eastern gray squirrels (Sciurus carolinensis), flight initiation distance did increase at lower gradients of human disturbance (Cooper et al. 2008; Engelhardt and Weladji 2011). Engelhardt and Weladji's (2011) study also looked at how the distance to safety affected the flight initiation distance and found it made no difference, which is comparable to my result that the mean flight initiation distances are similar regardless of whether the squirrel was out in the open, under bush cover, on the ground or just off the ground when approached. This result contradicts my prediction that the proximity to safety (bush cover and/or off the ground) would decrease the flight initiation distance, as was demonstrated by Dill and Houtman (1989) in eastern grey squirrels when using a stuffed cat (Felis domesticus) as a model predator.

It is possible that only a small number of encounters with humans are needed to cause squirrels to become habituated to their presence, as animals can use learning and experience to alter their responses to local predators (Deecke et al. 2002; Engelhardt and Weladji 2011; McCleery 2009). I did not sample any areas where humans would be completely novel to squirrels; I assumed that all squirrels within my sample areas would have had some exposure to humans. Given that red squirrels are highly adaptable (Bayne and Hobson 1998; Bayne and Hobson 2000), they may learn very quickly that humans are not a predator in the traditional sense. According to the optimal escape theory, red squirrels would benefit from adapting their flight initiation distance to local predators; particularly in the case of humans where predation risk would be low, squirrels would benefit from shorter flight initiation 
distances due to the energetic costs of fleeing (Cooper and Frederick 2007; Engelhardt and Weladji 2011). In a study performed by McCleery (2009), naïve juvenile fox squirrels (Sciurus niger) did have increased flight initiation distances when compared to experienced adults in urban settings; this supports the idea that squirrels become habituated to people with exposure.

An alternate explanation for a lack of significant differences in mean flight initiation distances across sites could be the time of year. At this time of year (late summer), squirrels are busy foraging to collect enough food to survive the winter (Brigham and Geiser 2012). When balancing benefits with costs of fleeing or staying and risking predation (Cooper and Frederick 2007; Engelhardt and Weladji 2011), squirrels may learn that humans pose low predation risk; thus, the benefit of continuing to forage is high. Squirrels with little exposure to humans could be making the same choice as squirrels with more exposure, as there is more to gain by continuing to forage at this time of the year.

Another possible compounding variable to explain the lack of observed significant difference in flight initiation distances across sites may include intraspecific competition. Bayne and Hobson (2000) found that habitat fragmentation in a similar nearby study site resulted in higher local densities of red squirrels, while red squirrel density in continuous forest was recorded as one individual per 0.65 hectares (Larsen and Boutin 1994). I estimate that each site I sampled was well within one hectare and I sampled anywhere from three to ten squirrels at any given site, which suggests a high local red squirrel population density. High densities of squirrels could affect cost and benefit decisions of staying versus fleeing, as competition for resources would be higher. This may also speak to my classification of the disturbance types: high population densities at all sites suggests that all areas saw habitat fragmentation caused by human disturbance, so the degree of disturbance between sites may not have been different enough to see significant differences in mean flight initiation distances. Ironically, as human disturbance may provide artificial food sources, humans may actually help support high red squirrel population densities due to habitat fragmentation (Bayne and Hobson 2000).

Possible explanations for the lack of observed significant differences in flight initiation distance between disturbance levels include fast learning by squirrels that humans are not traditional predators, the time of year biasing the benefit of remaining to forage, and/or a high squirrel density intensifying competition for resources. To establish if North American red squirrels become habituated to living around people in Saskatchewan, studies across a more diverse gradient of human disturbance with naive squirrels are needed.

\section{Acknowledgements}

I thank Dr. Karen Wiebe and Scott Halpin for their advice and guidance on experimental design, as well as logistical support during data collection. Special thanks to Dr. Wiebe for her assistance with statistical analyses and editing, and the anonymous reviewers for their helpful feedback on earlier versions of this paper. 


\section{References}

Bayne, E., and Hobson, K. 1998. The effects of habitat fragmentation by forestry and agriculture on the abundance of small mammals in the southern boreal mixedwood forest. Canadian Journal of Zoology 76:62-69.

Bayne, E., and Hobson, K. 2000. Relative use of contiguous and fragmented boreal forest by red squirrels (Tamiasciurus hudsonicus). Canadian Journal of Zoology 78:359-365.

Brigham, R.M., and Geiser, F. 2012. Do red squirrels (Tamiasciurus hudsonicus) use daily torpor during winter? Ecoscience 19:127-132.

Cooper, C.A., Neff, A.J., Poon, D.P., and Smith, G.R. 2008. Behavioral responses of eastern gray squirrels in suburban habitats differing in human activity levels. Northeastern Naturalist 15: 619-625.

Cooper, W.E., Jr., and Frederick, W.G. 2007. Optimal flight initiation distance. Journal of Theoretical Biology 244:59-67.

Deecke, V.B., Slater, P.J.B., and Ford, J.K.B. 2002. Selective habituation shapes acoustic predator recognition in harbour seals. Nature 420:171-173.

Dill, L.M., and Houtman, R. 1989. The influence of distance to refuge on flight initiation distance in the gray squirrel (Sciurus carolinensis). Canadian Journal of Zoology 67: 233-235.

Engelhardt, S.C., and Weladji, R.B. 2011. Effects of levels of human exposure on flight initiation distance and distance to refuge in foraging eastern grey squirrels (Sciurus carolinensis). Canadian Journal of Zoology 89:823-830.

Larsen, K.W., and Boutin, S. 1994. Movements, survival and settlement of red squirrel (Tamiasciurus hudsonicus) offspring. Ecology 75:214-223.

Larsen, K.W., and Boutin, S. 1995. Exploring territory quality in the North American red squirrel through removal experiments. Canadian Journal of Zoology 73:1115-1122.
McCleery, R.A. 2009. Changes in fox squirrel anti-predator behaviours across the urban-rural gradient. Landscape Ecology 24:483-493. 


\section{Appendix}

Table 1: Results of 39 red squirrel (Tamiasciurus hudsonicus) flight initiation distance measures taken in central Saskatchewan in August 2014 ( $*$ =not included in analyses).

\begin{tabular}{|c|c|c|c|c|c|c|}
\hline Location & Disturbance level & Time $(24 \mathrm{~h})$ & Flight Distance (m) & Position & Cover & Vocalization \\
\hline Kenderdine & low & 9:27 & 1.42 & ground & bush & no \\
\hline Kinasao Forest & low & 9:30 & 6.20 & ground & bush & yes \\
\hline Kenderdine & low & 9:35 & 2.87 & ground & bush & no \\
\hline Kenderdine & low & 9:38 & 6.96 & ground & open & no \\
\hline Kenderdine & low & $9: 40$ & 9.70 & ground & open & no \\
\hline Kinasao Forest* & low* & $9: 49 *$ & $3.15^{*}$ & tree* & bush* & yes \\
\hline Kenderdine & low & $10: 16$ & 4.38 & ground & open & no \\
\hline Kenderdine & low & $10: 20$ & 2.30 & ground & bush & no \\
\hline Kinasao Forest & low & $10: 41$ & 5.69 & ground & open & no \\
\hline Kenderdine & low & $10: 47$ & $3 \cdot 31$ & ground & open & no \\
\hline Kenderdine & low & $11: 00$ & 2.55 & off ground & bush & no \\
\hline Kenderdine & low & 11:01 & 4.07 & ground & open & no \\
\hline Kenderdine & low & $11: 21$ & 6.54 & ground & bush & yes \\
\hline Kenderdine & low & $11: 27$ & 8.28 & ground & open & no \\
\hline Murray Point & medium & $11: 52$ & 16.7 & off ground & bush & yes \\
\hline Murray Point & medium & $12: 04$ & 4.46 & off ground & bush & no \\
\hline Murray Point & medium & $12: 13$ & 3.39 & off ground & bush & yes \\
\hline Murray Point & medium & $12: 27$ & 11.7 & ground & bush & yes \\
\hline Murray Point & medium & $12: 39$ & 8.94 & ground & bush & yes \\
\hline Murray Point & medium & $12: 45$ & 2.14 & ground & bush & yes \\
\hline Murray Point & medium & $12: 51$ & $5 \cdot 56$ & ground & bush & yes \\
\hline Murray Point & medium & $12: 55$ & 3.07 & ground & bush & no \\
\hline Murray Point & medium & $13: 07$ & 9.92 & ground & open & no \\
\hline Okema trail & medium & $14: 27$ & 3.20 & ground & bush & yes \\
\hline Kinasao Site & high & $9: 43$ & 1.90 & ground & bush & no \\
\hline Residential CL & high & $10: 35$ & 0.80 & off ground & open & no \\
\hline Residential CL & high & $10: 39$ & 1.27 & off ground & open & no \\
\hline Residential CL & high & $11: 43$ & 3.47 & ground & open & no \\
\hline Residential CL* & high* & 11:56* & $1.60 *$ & tree* & bush* & yes \\
\hline Residential EL & high & $12: 00$ & 6.74 & ground & open & no \\
\hline Residential EL & high & $12: 27$ & 3.49 & ground & bush & yes \\
\hline Residential EL & high & $12: 47$ & 11.0 & ground & open & no \\
\hline Residential EL & high & $13: 40$ & 4.58 & off ground & bush & yes \\
\hline Residential EL & high & $13: 50$ & 4.96 & ground & open & no \\
\hline Residential EL* & high* & $13: 59^{*}$ & $1.68 *$ & tree* & bush* & yes \\
\hline Residential CL & high & 14:03 & 2.18 & off ground & open & yes \\
\hline Residential EL & high & $14: 43$ & 3.20 & ground & open & no \\
\hline Kinasao Site & high & 19:06 & 11.3 & ground & open & no \\
\hline Kinasao Site & high & $19: 12$ & 0.590 & ground & open & no \\
\hline
\end{tabular}


Squirrel Habituation in Human Disturbed Areas (Bjordal)

University of Saskatchewan Undergraduate Research Journal 